\title{
CRÍTICA ACÉFALA
}

Daniel Link

ANTELO, Raúl. Crítica acéfala. Buenos Aires: Editora Grumo, 2008. 274 págs.

En el sistema de archivos de mi disco rígido hay una serie de carpetas, cuyas primeras entradas copio: Abralic, Agendas, Alban, Alquileres, Amazon, Antelo, Asociaciones, Becas, Blog. No es una clasificación sistemática, porque Alban debería depender de Becas, y Abralic, naturalmente, de Asociaciones. Pero además no sé para qué tengo una carpeta llamada Asociaciones siendo tan pocas de las que participo, y con espíritu tan agónico y tan intermitente. Es probable que la única lógica que pueda aplicarse a la serie sea la de los estratos. Cada nombre corresponde a un estrato geológico e involucra, por lo tanto, una variable temporal: una acumulación insensata de designaciones que la pereza o el signo de los tiempos me impiden clasificar correctamente.

La carpeta Abralic y, más adelante, la carpeta Mercosur, tienen con la carpeta Antelo una relación de presuposición, pero eso sólo lo sabe mi conciencia. El sistema digital de archivos nada dice sobre el tiempo y las relaciones de mutua implicación entre una carpeta y otra quedarán libradas a la imaginación del lector ocasional de esos papeles virtuales. La carpeta Antelo es de las más antiguas, y la que más tesoros guarda. Muchos de los textos que ahí se acumulan, sin orden ni concierto, forman ahora parte de Crítica acéfala, el último libro de Raúl Antelo, cuya aparición venimos a festejar. Otros, sin embargo, no.

Podría detenerme en la confrontación de esos pre-textos con este libro majestuoso y de una sabiduría infinita que Antelo una vez más nos regala, cuando todavía no alcanzamos a reponernos de la impresión que su María con Marcel nos había provocado ${ }^{1}$. Pero prefiero postergar ese esfuerzo de crítica genética (para la cual, por otra parte, no creo tener talento alguno): alguna vez

1 Cfr. mi reseña a ese libro en la revista Margens / Márgenes, 2007. 
habrá un editor que encargará el trabajo, así lo espero, de ordenar y comentar la obra anteliana y eso sucederá, sencillamente, porque Raúl Antelo ocupa ya un lugar tan destacado en la teoría y la crítica latinoamericanas que su obra inmensa deberá alimentar a las futuras generaciones de nuestro continente.

Si me demoro en estos circunloquios sobre mi sistema de archivos y la obra de Antelo es porque quiero que se entienda por qué he aceptado, no sin temeridad, la invitación de Grumo a presentar Crítica acéfala: hace años que convivo con estos textos, cuyo hermetismo muchas veces me subleva y, después de haberlos releído tantas veces y de haberlos usado con la actitud del buen salvaje que se prueba las mejores joyas de una cultura extravagante para su torpe comprensión, creo que puedo insinuar algunas hipótesis sobre el dispostivo crítico que llamamos (que reconocemos como) Antelo, que no se compara con ningún otro y que garantiza que encontremos, en él, un pensamiento (es decir: algo cuya existencia se impone a quien no lo pensó). Decir que hay pensamiento en Antelo es decir que existen en su obra proposiciones. Pero nada existe si no tiene propiedades. $Y$ nada tiene propiedades si éstas no son, parcialmente al menos, independientes del medio. Hay que establecer que existen en Antelo proposiciones suficientemente sólidas como para ser extraídas de su propio campo, para soportar cambios de posición y modificaciones del espacio discursivo. No es necesario, en este punto, ser exhaustivos: basta con que algunas propiedades de ese tipo sean reconocidas para algunas proposiciones ${ }^{2}$.

He dicho "obra de Antelo" y he dicho "hermetismo". Quisiera realizar algunas precisiones y correcciones al respecto. Bien leída, la obra de Antelo, que lo es precisamente en el instante en que se separa de la monografía y de los protocolos escolásticos previstos por las universidades, no es hermética (nada que ver con los círculos de Hermes), sino exotérica: lo es porque se dirige a quienes están fuera de la comunidad filosófica (exo) y no han elegido todavía el modo de vida teórico. Al proponerse como "obra", entonces, el pensamiento se coloca a igual distancia de la locura (la ausencia de obra) y de

2 Jean-Claude Milner. La obra clara. Lacan, la ciencia, la filosofía. Buenos Aires, Manantial, 1996 
la ciencia (la ausencia de nombres propios), y al proponerse como obra exotérica, los textos reunidos en Crítica acéfala recurren a la protréptica como manera de arrancar al sujeto de la doxa ${ }^{3}$. La protréptica asume, en el espacio del párrafo escrito, la forma atécnica de la conversación erudita, que no pudiendo desplegarse según la formalización del diálogo, se entrega al excursus, a la palabra rara, a la sintaxis tortuosa, al juego con los significantes que impiden al lector, participante de una época (la nuestra) que, como ninguna otra, se revela enemiga radical del pensamiento, abandonarse a su inclinación de lengua ("la lengua es fascista"), y lo hacen desconfiar de las sucesiones lineales y las disposiciones simétricas, lo obligan al saber que vendrá.

La protréptica de Antelo, pienso ahora, forma parte de una estrategia de seducción. Leer el pensamiento en su obra es desembarazar a sus textos de las oscuridades que arroja ocasionalmente en ellos la protréptica, que sin embargo no debe entenderse como un mero suplemento de escritura sino como algo constitutivo del dispositivo crítico.

Por supuesto, la protréptica negativa pasa por Macrobio ${ }^{4}$ (cuya obra es una de las condiciones de posibilidad del viaje colombino) y, por intermedio de La Mothe Le Vayer" ${ }^{5}$, llega a "Kant con Sade" de Lacan, texto profusamente citado en Crítica acéfala y que seguramente lo es tanto por sus enunciados como por el tipo de enunciación.

$\mathrm{Si}$ es cierto que Crítica acéfala hace un uso despiadadamente quirúrgico de las invenciones más contemporáneas de la filosofía y de la crítica (Derrida, Agamben, Nancy) revelándonos autores, obras y tendencias de pensamiento de antes de ayer y de mañana, no menos cierto es que vuelve con obsesión maníaca a un puñado de nombres propios (Bataille, Caillois, Leiris, Lacan) ligados con un proyecto teórico que representa la parte maldita

3 En el Eutidemo, Sócrates la postula como un saber que exhorta a aprender la virtud y a convencer a otros a que también la aprendan y la practiquen. Cfr. Platón. Euthidème (traduction nouvelle, introduction et notes par Monique Canto). París, Flammarion, 1989. "Ce dialogue paraît donner le premier exposé extensif d'un protreptique, et, sans doute, la consécration philosophique du genre" (p. 60; subrayado mío).

4 Escritor y gramático romano del último cuarto del siglo IV, autor de las Saturnalia, un simposio literario incompleto en siete libros, los Commentarii in Somnium Scipionis y De differentiis et societatibus Graeci Latinique verbi, tratado gramatical perdido. La importancia de Macrobio es decisiva en Dante, Bocaccio, Cervantes y se lo considera uno de los responsables, por ejemplo, de que entre los geógrafos medievales persistiera la creencia en la esfericidad de la Tierra.

5 François de La Mothe Le Vayer (1588-1672), escritor francés, miembro de la Academia a partir de de 1639, tutor de Luis XIV. 
del siglo $\mathrm{XX}$, el pensamiento menos heroico $\mathrm{y}$, al mismo tiempo, el más desafortunado, el que con más dificultades se ha topado para su comprensión. No es casual, entonces, que en Crítica acéfala Antelo describa el lugar, que tal vez sea su lugar, de acefalía: "El crítico ocupa un intersticio de ficción y teoría. Aunque ése es su lugar singular, nada tiene de desinteresado. Muy por el contrario, en el interés (...) se aviva su pasión por leer y comprender. Inter legere, ser intelectual, poder pensar la experiencia" (pág. 9).

¿Pero cómo se piensa la experiencia cuando el siglo $X X$ nos ha alertado repetidas veces sobre su imposibilidad? Pues bien, afirmando al mismo tiempo esa imposibilidad y su necesidad, y haciendo con esa paradójica posición de inclusión externa de la experiencia en las tensiones de nuestro tiempo, el programa de una ética.

En la perspectiva del dispositivo crítico que se deduce de Crítica acéfala, la primera proposición que reconocemos es precisamente la imposibilidad de sostener una estética sin ética o, lo que es lo mismo: la indecibilidad de los límites entre ética y estética. Todas las circunvalaciones que el dispositivo propone en relación con esas dos palabras ("anestética", "hiperestesia", "anestesia", "curare", "pharmacon") no sirven sino para transformar el límite de lo estético (límite en relación con el cual también se despliega toda una familia aberrante de palabras) en el umbral de lo ético: "En ese sitio-guion, ni plenamente mimético, ni totalmente mágico, sino ético, se esboza un más allá del sujeto y un más allá de lo moderno" (pág. 28).

Esa modernidad que aquí se cita podrá parecer, a quienes todavía se aferran al salvavidas de la imaginación dialéctica mientras las arpas y los violines acompañan el hundimiento del crucero, una modernidad singular, como lo quiere la escuela, pero a lo largo de Crítica acéfala queda claro que se trata de un campo de tensiones respecto de las cuales pueden situarse multiples singularidades: una de ellas será la modernidad autónoma, que produce "aquellas lecturas que enfatizan lo estético para mejor eludir los efectos éticos allí implicados" (pág. 220) y que el dispositivo crítico de Antelo rechaza, como rechaza las imágenes plenas y los señuelos de la representación. Pero también la singularidad de la modernidad anautónoma o heterológica, en relación con la cual el dispositivo Antelo se desborda: "la modernidad misma es un guión, un 
roteiro o derrotero, un movimiento en dirección al movimiento pero también una secuencia de discontinuidades" (pág. 13). Contra el borde pleno y maniáticamente delimitado, la grieta y la falla a través de las cuales se cuelan los vientos de la historia. Contra la frontera, el extravío. Contra la reificación del "lugar geocultural como causa final de la discursividad crítica" (pág. 67), una contramodernidad "más apta para desconstruir la lógica coercitiva de la misma modernidad". (pág. 68). Contra la modernidad periférica, la excentricidad y el descentramiento. Contra la colección, la serie. Segunda proposición, entonces: no hay modernidad (no puede haberla en singular, porque la modernidad no es un hecho histórico sino una construcción teórica), sino modernidades, y cada una de ellas se reconoce por un tipo de negatividad ${ }^{6}$.

En ese umbral entre lo ético y lo estético se construye el dispositivo de lectura (el dispositivo para pensar la experiencia), ese compuesto de ficción y teoría que, además, puede subdividirse al infinito según la lógica del retardo, ya que, además: "Lo ficcional se define (...) como el punto medio entre la atracción de lo desconocido y la apariencia del ser" (pág. 112).

Esa ética, que no es propiamente una ética del renunciamiento ni del abandono, sino algo más complejo que por el momento se nos escapa, es lo que permite definir el campo de actuación del dispositivo crítico. Tercera proposición: lo único interesante es la experiencia de lo latinoamericano. Raúl Antelo, que podría hablar con autoridad y, además, con inteligencia, de cualquier cosa, encuentra un espacio que, al mismo tiempo que lo hostiga, estimula al pensamiento: se trata de pensar América Latina y de imaginar, además, una situación geopolítica (la crisis y la guerra) según la cual Latinoamérica sea el modelo del mundo y modelo de pensamiento del mundo. Por supuesto, se trata de lo imaginario, y de devolverle a lo imaginario un porvenir, de volver a hacer de él una categoría de futuro ${ }^{7}$. Así, Crítica acéfala retoma de Nietzsche "una ética del desbordamiento y la entrada en los otros

6 En Crítica acéfala se reconocen dos tipos de negación: la negación dialéctica y la negación acefálica, que otros llamarían sencillamente transgresión, pero que Antelo decide alejar de esa lógica que la cultura industrial de la segunda mitad del siglo XX vulgarizó y neutralizó en su potencia negativa. Cfr., por ejemplo, pág. 59 y siguientes. Sobre la negatividad sin resto de Bataille ver asimismo Lo abierto. El hombre y el animal de Giorgio Agamben (Valencia, Pretextos, 2005, pág. 15 y siguientes). Sobre transgresión y ascesis como formas de negatividad, cfr. Didier Eribon. Una moral de lo minoritario. Barcelona, Anagrama, 2004.

7 Éric Marty. Roland Barthes, el oficio de escribir. Buenos Aires, Manantial, 2007 
que puede sernos provechosa en la actual coyuntura de lo argentino-brasileño" (pág. 28). En María con $\mathrm{Marcel}^{8}$ se dejaba leer la hipótesis, extravagante y, por eso mismo, encantatoria, de que Duchamp no habría llegado a nada sin la experiencia de lo americano (una categoría que incluye, o debería incluir, por supuesto, a los Estados Unidos). En Crítica acéfala se insiste, por otras vías, en la misma dirección de pensamiento: América es el Occidente de Occidente y no, como alucinaba Colón (discípulo de Macrobio), su Oriente. Al contrario de lo que pensaba Lévy-Strauss, ese enemigo de Caillois, América no es el reflejo "de una época en que la especie era a la medida de su universo y donde persistía una relación válida entre el ejercicio de la libertad y sus signos" ${ }^{9}$, no es propiamente el pasado de Europa sino, paradójicamente, su futuro, la cifra del des-astre ("el sentido aparece con la intensidad del desastre, es decir, aquello que va a borrarse o está a punto de desaparecer", escribe Antelo ${ }^{10}$ ), el lugar radical del destierro, de la desterritorialización del pensamiento.

Uno de los operadores del dispositivo crítico es la reversión temporal, como cita del eterno retorno en tanto lógica de la historia y cifra, por lo tanto, de la singularidad histórica. Así, para evaluar la perspectiva del poscolonialismo y sus cultores, el dispositivo retrocede a una escena del 15 de marzo de 1942, cuando "Roger Caillois le escribe una carta a su amiga y protectora, Victoria Ocampo" (pág. 68) e, inmediatamente, a una "situación previa" de 1938. Para comprender la poesía de Arturo Carrera, "podemos remontarnos a Alfred Métraux, especialista en antropofagia tupinambá y director del Instituto de Etnografía de la Universidad de Tucumán, quien registraba en su diario de 1931, al atravesar el altiplano boliviano, que recién en Chipaya logró comprender la íntima cohesión económica que vincula a toda la humanidad" (pág. 250).

Un poco por eso, simplificando un poco los tortuosos senderos que el dispositivo Antelo nos obliga a transitar, Foucault no habría llegado a nada sin Bataille (o habría llegado más temprano al modelo de negatividad que usó en sus últimos escritos si hubiera podido desembarazarse antes de la noción de transgresión), y Bataille no habría llegado a nada sin Métraux, y Métraux no

8 María con Marcel. Duchamp en los trópicos. Buenos Aires, Siglo XXI, 2006

9 Cfr. Tristes trópicos. Barcelona, Paidós, 1988, pág. 154.

10 pág. 263. 
habría llegado a nada sin Tucumán y la antropofagia ritual tupí-guaraní. Ergo: hasta el primer volumen de la Historia de la sexualidad, Foucault es guaraní. Recién después se vuelve griego.

*

Así planteado, el dispositivo crítico se nos revela con toda su fuerza y se entienden mejor los rodeos, los retardos, los excursi, la torsión agónica de las palabras ${ }^{11}$, los laberintos temáticos, las conclusiones inesperadas y las filiaciones teóricas insospechadas (Agamben y Derrida como continuación de Bataille, por ejemplo ${ }^{12}$, o Bataille detrás de cada frase alguna vez escrita por todos y cualquiera ${ }^{13}$ ): se trata, naturalmente, del dispositivo crítico paranoico,

11 "Rama no firma la reseña; lo hace su otro, Antonio Gundin, nombre que suena como apellido de banquero brasileño, suerte de alter-ego del líder nacionalista Gondim da Fonseca, autor de una historia del periodismo carioca, aunque también evoque al personaje Gondim de Gracialiano Ramos (São Bernardo). Pero, simultaneamente, en ese Gundín pulsa también lo bajo y transgresivo, el perigundín, el bordel. Esa tensión entre lo alto y lo bajo, lo viejo y lo nuevo, alimenta pues toda la argumentación de Rama. Podríamos decir que, en su evaluación del caso Glauber Rocha, el crítico reproduce la tensión entre dos modelos de estética revolucionaria, Eisenstein x Brecht." (pág. 200)

12 En Lo abierto. El hombre y el animal (Valencia, Pretextos, 2005) queda claro que Giorgio Agamben y Georges Bataille comparte ciertos intereses, pero también que sus posiciones son irreductibles.

13 Discípulo de Antelo como me reconozco, propongo el siguiente ejercicio. En la entrevista apócrifa a Marcola, jefe de la banda carcelaria de San Pablo denominada Primer Comando de la Capital, publicada por el diario O globo, se lee:

\section{"-¿Usted no tiene miedo de morir?}

-Ustedes son los que tienen miedo de morir, yo no. Mejor cárcel, ustedes no pueden entrar y matarme, pero yo puedo mandar matarlos a ustedes allí afuera. Nosotros somos hombresbombas. En las villas miseria hay cien mil hombres-bombas. Estamos en el centro de lo insoluble mismo. Ustedes en el bien y el mal y, en medio, la frontera de la muerte, la única frontera. Ya somos una nueva "especie", ya somos otros bichos, diferentes a ustedes. La muerte para ustedes es un drama cristiano en una cama, por un ataque al corazón. La muerte para nosotros es la comida diaria, tirados en una fosa común. ¿Ustedes intelectuales no hablan de lucha de clases, de ser marginal, ser héroe? Entonces ¡llegamos nosotros! ¡Ja, ja, ja.! Yo leo mucho; leí 3000 libros y leo al Dante, pero mis soldados son extrañas anomalías del desarrollo torcido de este país. No hay más proletarios, o infelices, o explotados. Hay una tercera cosa creciendo allí afuera, cultivada en el barro, educándose en el más absoluto analfabetismo, diplomándose en las cárceles, como un monstruo Alien escondido en los rincones de la ciudad. Ya surgió un nuevo lenguaje. ¿Ustedes no escuchan las grabaciones hechas "con autorización" de la justicia? Es eso. Es otra lengua. Está delante de una especie de post miseria. Eso. La post miseria genera una nueva cultura asesina, ayudada por la tecnología, satélites, celulares, Internet, armas modernas. Es la mierda con chips, con megabytes. Mis comandados son una mutación de la especie social. Son hongos de un gran error sucio". Podrìamos pensar que esas palabras, no importa quien las haya articulado, ya habían sido anunciadas por Bataille en su comentario a Voyage au bout de la nuit en La Critique sociale (París: enero de 1933): "Ya no es tiempo de jugar el juego irrisorio de Zola que obtiene su grandeza de la desgracia de los hombres y que se conserva él mismo ajeno a los miserables. Aquello que aísla al Viaje al fin de la noche y le da su significación humana es el intercambio de vida realizado con aquellos a los que la miseria arroja fuera de la humanidad -intercambio de vida y de muerte, de muerte y de 
que no es, como lo revela la reversión temporal, sino una variación moderna del potlatch (pág. 252). Cuarta proposición: el conocimiento será paranoico (por método y dispositivo), o no será.

No se trata, claro, de una conciencia paranoica como la que se expresa en el libro más emblemático de la Europa en guerra de la década del treinta, Viaje al fin de la noche de Céline (cuyo mayor admirador entre sus contemporáneos no fue ni Lévy-Strauss, ni Paul Nizan, ni, por cierto, Trotsky, sino Bataille ${ }^{14}$ ). No, el crítico inter no es Bardamu, y su situación no es la del enfermo cuya voluntad no tiene efecto sobre su cuerpo: "L'anarchie partout, et dans l'arche, moi Noé gâteux" ${ }^{15}$. La licuefacción de la realidad, tal como se presenta a Bardamu (tal como se presenta a la imaginación milenarista de la que Bardamu participa), lo transforma (por la vía de los automatismos corporales) en un Noé paranoico que no encuentra qué salvar porque la idea de colección (propia de la imaginación humanista) se ha vuelto imposible. La licuefacción del paisaje que se deja leer en Viaje al fin de la noche es correlativa de la licuefacción de la conciencia (acuificación diluvial) y aparece en serie con los sólidos blandos de Salvador Dalí, que fue precisamente quien propuso en la década del treinta y en la misma revista donde colaboraban Lacan y Bataille, un método crítico-paranoico ${ }^{16}$ con el cual el dispositivo de Antelo se relaciona, aún con las enormes distancias que pueden señalarse entre ambos (el lugar del azar, por ejemplo): "la experiencia paranoica afianza, como quería Lacan, la comunidad humana, esa misma comunidad que Dalí perseguía gracias a la hiperagudeza objetiva y comunicable del fenómeno ficcional, pero que, en último análisis, nos plantea siempre el problema de la ausencia de comunidad" (pág. 78).

En el caso de Crítica acéfala, la paranoia no es una propiedad de la conciencia sino del dispositivo que, por eso mismo, vuelve una y otra vez a la

decadencia: una cierta decadencia que está en la base de la fraternidad cuando la fraternidad consiste en renunciar a demasiados reclamos y a una conciencia demasiado personales, con el fin de hacer suyos los reclamos y la conciencia de la miseria, es decir, de la existencia de la mayoría". Cfr. André Derval (comp.). Voyage au bout de la nuit. Critiques 1932-1935. Paris, Imec, 2005, pàg. 170.

14 op. cit.

15 Louis-Ferdinand Céline. Voyage au bout de la nuit. Paris, Gallimard, 2005, pág. 175. "La anarquía por todas partes y en el arca, yo, Noé, medio lelo" (pág. 219 en la traducción castellana: Viaje al fin de la noche. Barcelona, Edhasa, 2004).

16 Sobre el método crítico-paranoico de Dalí, cfr. Daniel Link. "Cómo se lee" en Cómo se lee y otras intervenciones críticas. Buenos Aires, Norma, 2003. 
década del treinta, esa singularidad histórica en la que la humanidad se hundió no tanto en un pozo de ignominia (lo que es cierto) sino en un vacío de imaginación y en un deseo de sentido. La década del treinta es la década de la crisis del capitalismo pero, sobre todo, la década de la humanidad en guerra, y Critica acéfala no es sino del despliegue obsesivo de un pensamiento sobre la crisis y la guerra. Contra ese vacío, contra el problema de la ausencia de comunidad, y a favor del deseo, alrededor de la crisis y la guerra, entonces, el dispositivo paranoico levanta su fuerza antidogmática, proponiendo una relación entre lugares distantes que no responde ni a la escolástica universitaria ni tampoco a los procesos de abducción, sino a esa potencia adivinatoria de lo inter (entre la ficción y la teoría). "Como Duchamp no desarrolló las consecuencias teóricas de su trabajo, podríamos pensar", escribe Antelo, "que cupo a Bataille hacerlo a través del postulado de un dominio heterológico o sagrado, compuesto por fenómenos que escapan a la reducción intelectual y sólo admiten ser definidos en negativo, como diferencia no-lógica o inexplicable en términos argumentativos" (pág. 37, yo subrayo).

Por supuesto, podríamos pensar eso, y también cualquier otra cosa. Ese "podríamos pensar", que vuelve como un ritornello (con sus variaciones: "podríamos decir, entonces,...", pág. 252) a lo largo de todo Crítica acéfala, es el operador central del dispositivo crítico: se trata de pensar lo impensado. No hay otra fuerza ni otro sentido para el intelectual y para su obra, aún cuando para pensar lo impensado se vuelvan irreconocibles las doctrinas y la opacidad de la protréptica invada el discurso (después de todo, invenio y dispositio son dos caras de la misma moneda).

Si fuera cierto (como muchos sugieren) que el dispositivo Antelo se inscribe en las corrientes críticas lacanianas, lo sería no tanto por la aplicación fiel de un modelo analítico o por la reproducción de una jerga o un juego de conceptos, cosa que nunca hace, sino por el reconocimiento, como ha señalado Deleuze, de que "toda la fuerza de Lacan es haber hecho pasar al psicoanálisis del aparato edípico a la máquina paranoica. Hay un significante mayor que subsume los signos, que los mantiene en el sistema de masa, que organiza su red. Me parece que ése es el criterio del delirio paranoico, es el 
fenómeno de la red de signos, donde el signo remite al signo" ${ }^{17}$.

Ese dispositivo es antidogmático porque hace resonar en los textos las voces que se quieran, con independencia de lo que realmente estén diciendo, y en ese carrousell de voces el sentido, en lugar de adelgazarse hasta la asignificancia (hipótesis más adecuada a la imaginación pop), se vuelve un híbrido monstruoso, como si dijéramos: un minotauro.

"Inscripto, pues, en la tradición de ambivalencia de lo sagrado, inaugurada por Bataille en los años 30, Glauber se depara con el valor sacer (Agamben) que es el del pueblo en falta (Deleuze), el de la multitud inorgánica" (pág. 211). En esta cita, podríamos pensar, se encuentran todas las partes del dispositivo: la acumulación insensata, los nombres propios como joyas ${ }^{18}$ (característica de la máquina de guerra que se opone a la ciencia de Estado ${ }^{19}$ ), la correlación aberrante, el híbrido semántico, la protréptica y la adivinación: "toda adivinación, como la de la alea o la del aleph, sobrepasa en mucho los acontecimientos posibles, cuyo número infinito no cesa de bifurcarse de modo incontrolado, aunque no menos previsible, ya que la certidumbre permanece siempre excluida de ese juego particular. La verdad, en suma, falta siempre en su lugar" (pág. 64).

Aún cuando la apariencia del discurso pudiera intentar persuadirnos de lo contrario, por la vía del dispositivo paranoico el pensamiento escapa así a dos coerciones: el saber de la estructura y el saber de la muerte ${ }^{20}$ : el recurso conjetural o adivinatorio del dispositivo preserva el pensamiento allí donde lo supone amenazado por la doxa, el parloteo de la repetición y el pánico (el pánico ante la guerra).

17 Gilles Deleuze. Cours Vincennes: fragments. Anti OEdipe et Mille Plateaux. Clase del 12/02/1973 sobre el Cuerpo Sin Órganos.

18 Otro ejemplo: "No es casual, en ese sentido, que la primera edición de Fata Morgana, la obra de Breton, editada por Caillois en Buenos Aires, haya sido ilustrada por Wilfredo Lam" (pág. 44). Para el dispositivo paranoico, por otra parte, nada es casual: "No es fortuito, entonces que, en la actual poesía argentina, Arturo Carrera sea quien mejor ilustre la conciencia de esa paradoja poetológica" (pág. 253)

19 Cfr. Gilles Deleuze y Felix Guattari. Mil mesetas. Capitalismo y esquizofrenia. Valencia, Pretextos, 1988

20 Éric Marty. op. cit. 
Crítica acéfala reúne catorce ensayos de Raúl Antelo, organizados en tres apartados: "Acéfalo", "Borges" y "Lenguajes". En algún lugar de su curso La hermenéutica del sujeto ${ }^{21}$, Foucault recordaba una de las máximas estoicas: no se trata de leer muchos libros, sino de leer unos pocos, los que verdaderamente importan, y pensar mucho en ellos. Todos los de Raúl Antelo integrarían esa categoría, pero especialmente Crítica acéfala, que recibimos como un regalo precioso que nos obligará a meditar durante largo tiempo. Quinta y última proposición: el pensamiento nos llega como un don.

Buenos Aires, 2 de julio de 2008 